\title{
Armazenamento a frio e aplicação de reguladores vegetais no enraizamento de estacas radiculares e caulinares de framboeseira
}

\author{
Cold storage and treatment with plant growth regulators in rooting of root \\ and stems cutting of raspberry
}

\begin{abstract}
Andrei Spaziani Tiberti ${ }^{\mathrm{I}}$ Flávio Gabriel Bianchini ${ }^{\mathrm{I}}$ Rafael Pio ${ }^{\mathrm{I}^{*}}$ Paula Nogueira Curi Pedro Henrique Abreu Moura ${ }^{I}$ Maraísa Hellen Tadeu ${ }^{I}$
\end{abstract}

RESUMO

$O$ objetivo deste trabalho foi verificar o potencial rizogênico de estacas caulinares e radiculares da framboeseira (Rubus idaeus L.). Estacas da cultivar 'Batum'foram armazenadas a frio $\left(4^{\circ} \mathrm{C}\right)$ por 10,20 e 30 dias, além do controle sem armazenamento. Posteriormente, as estacas caulinares foram tratadas com ácido indolilbutírico (AIB) a 0, 1000, 2000, 3000 e 4000mg L $L^{-1}$ e as estacas radiculares com benzilaminopurina (BAP) a 0, 300, 600, 900, 1200 e 1500mg $L^{-1}$ por $10 \mathrm{~s}$. As estacas caulinares foram enterradas em 2/3 de seu comprimento, na posição vertical e as radiculares foram totalmente enterradas na posição horizontal, a três centímetros de profundidade. Utilizou-se vermiculita de grânulos médios como substrato, e estes experimentos foram conduzidos sob telado com sombreamento de 50\%. As avaliações foram feitas após 75 dias do plantio das estacas. Concluiu-se que o uso de estacas caulinares não é viável e que as estacas radiculares não necessitam ser estimuladas pelo armazenamento a frio ou do tratamento com BAP.

Palavras-chave: Rubus idaeus L., propagação, ácido indolilbutírico, benzilaminopurina.

\section{ABSTRACT}

The objective of this research was to verify the potential rhizogenic stem cuttings and root of raspberry (Rubus idaeus L.). Cuttings of 'Batum' cultivar was stored cold $\left(4^{\circ} \mathrm{C}\right)$ for 10,20 and 30 days, and a control without storage. Subsequently, the cuttings were treated with indolebutyric acid (IBA) at 0, 1000, 2000, 3000 and 4000mg L $\mathrm{L}^{-1}$ and root cuttings with benzylaminopurine (BAP) at 0, 300, 600, 900, 1200 and $1500 \mathrm{mg}^{-1}$ by 10 seconds. The cuttings were buried in $2 / 3$ of its length in the vertical position, and root was completely buried in the horizontal position at three inches deep. It was used vermiculite medium as substrate, and these experiments were conducted in a greenhouse with 50\% shading. Evaluations were made 75 days after planting the cuttings. It was concluded that the use of cuttings is not feasible and that the root cuttings need not be stimulated by cold storage or treatment with BAP.
Key words: Rubus idaeus L., propagation, indolebutyric acid, benzylamino purine.

\section{INDRODUÇÃO}

As frutas do gênero Rubus são muito apreciadas por suas características organolépticas (GUEDES et al., 2014), e, mais recentemente, também têm sido valorizadas pelos benefícios proporcionados à saúde, decorrentes dos elevados teores de antioxidantes, vitaminas, minerais, fibras, ácido fólico, entre outros (GUEDES et al., 2013; MARO et al., 2013; MARO et al., 2014). Dentre as opções de espécies frutíferas do gênero Rubus com boas perspectivas de comercialização e utilização na agroindústria familiar, destaca-se a framboeseira (Rubus idaeus L.), que é uma espécie ainda pouco cultivada no Brasil e que tem despertado grande interesse por diversos produtores (SILVA et al., 2012; CURI et al., 2014; SOUZA et al., 2014a; SOUZA et al., 2014b).

O cultivo da framboeseira no Brasil iniciou-se na década de 50, no município de Campos do Jordão-SP, por meio da introdução de algumas cultivares (PAGOT, 2006). Posteriormente, os cultivos foram expandidos para o sul do Brasil. Atualmente, os principais estados produtores são o Rio Grande do Sul, São Paulo e Minas Gerais, sendo a área total estimada em 150 hectares e produção anual de 300 toneladas (MARO et al., 2012). Em geral, a framboeseira pode se desenvolver em regiões com 250 a 300 horas de frio, abaixo de $7,2^{\circ} \mathrm{C}$, como

\footnotetext{
'Programa de Pós-graduação em Agronomia/Fitotecnia, Departamento de Agricultura (DAG), Universidade Federal de Lavras (UFLA),
} CP 3037, 37200-000, Lavras, MG, Brasil. E-mail: rafaelpio@dag.ufla.br. *Autor para correspondência. 
também existem cultivares, cujos requerimentos podem ser maiores que 1.000 horas de frio (RASEIRA et al., 2004).

De acordo com MOURA et al. (2012), framboeseiras da espécie $\boldsymbol{R}$. idaeus L. apresentam boa adaptação para as condições climáticas do sul de Minas Gerais, destacando-se entre as que produzem frutas de coloração vermelha, a cultivar 'Batum'. Existem poucas informações na literatura sobre esta cultivar. Há desconfiança de que se trate da cultivar 'Autumn Britten', que, no Brasil, tenha recebido, pelos produtores, o nome 'Britten' e, posteriormente, 'Batum' (RASEIRA et al., 2004). Ela apresenta produtividade estimada de $5 \mathrm{t} / \mathrm{ha}$, no primeiro ano pós-plantio (MOURA et al., 2012). Nessa região, as framboeseiras, que são menos exigentes em frio (250 horas), podem apresentar como vantagem a antecipação da colheita em relação a alguns estados da região sul do Brasil.

Mas, para que estas framboeseiras se desenvolvam bem nas condições climáticas do sul de Minas Gerais, deve ser feito um manejo diferenciado das plantas com relação à poda das hastes. Todas as hastes devem ser eliminadas por ocasião da poda de inverno, reduzindo-as, entre 5 e $10 \mathrm{~cm}$, da base da planta (MARO et al., 2012).

Devido a este manejo adotado, há grande disponibilidade de estacas caulinares, oriundas da poda de redução efetuada no inverno, que podem ser usadas na propagação da espécie. Estacas radiculares, obtidas fragmentando as raízes das hastes que brotam nas entrelinhas, também são usadas na produção de mudas desta fruteira (MARO et al., 2012; MOURA et al., 2012).

Existem técnicas que são empregadas visando ao aumento da emissão de raízes em estacas caulinares e radiculares. Uma delas é o armazenamento em ambiente refrigerado e úmido, cuja finalidade é suprir a necessidade de frio das gemas, em fruteiras de clima temperado (PATTO et al., 2013). Este armazenamento auxilia na superação da endodormência das gemas e propicia o aumento da emissão de brotações nas estacas (CELANT et al., 2010).

Outra técnica utilizada é o tratamento das estacas com reguladores vegetais. O ácido indolilbutírico (AIB) é uma auxina sintética que tem por finalidade aumentar a emissão de raízes em estacas caulinares (CHAGAS et al., 2008; HAN et al., 2009; PATTO et al., 2013).

Em estacas radiculares de amoreira-preta, a aplicação de citocininas pode auxiliar na emissão de brotações nessas estacas (CAMPAGNOLO \& PIO, 2012). A benzilaminopurina (BAP) tem se destacado entre as citocininas pela eficiência em induzir a formação de grande número de brotos e elevadas taxas de multiplicação in vitro de micro propágulos em framboeseira (LEITZKE et al., 2010).

Este trabalho teve como objetivo estudar o emprego do armazenamento em ambiente refrigerado e úmido e a aplicação de reguladores vegetais no enraizamento e brotação de estacas radiculares e caulinares de framboeseira.

\section{MATERIAL E MÉTODOS}

As estacas foram coletadas em plantas de framboeseira 'Batum', com quatro anos de idade, no final de junho de 2011, em pomar comercial, localizado em Senador Amaral-MG, no momento da poda invernal. O referido município localizase na serra da Mantiqueira, a $1.550 \mathrm{~m}$ de altitude, temperatura média anual de $18,2^{\circ} \mathrm{C}$, com temperaturas médias, nos meses mais frios do ano, de $10^{\circ} \mathrm{C}$ (junho e julho). O clima do município é Cwb.

Para o primeiro experimento, foram coletadas estacas caulinares de ramos lenhosos dormentes, que foram padronizadas $\mathrm{com} 15 \mathrm{~cm}$ de comprimento e diâmetro próximo a $8 \mathrm{~mm}$, realizandose corte perpendicular no ápice da estaca e outro, em bisel na base e removendo-se todas as folhas. No segundo experimento, foram coletadas estacas radiculares oriundas de hastes laterais, localizadas nas entrelinhas do plantio, as quais foram padronizadas com $10 \mathrm{~cm}$ de comprimento e diâmetro próximo a $10 \mathrm{~mm}$, com cortes perpendiculares em ambas as extremidades.

Em seguida, as estacas caulinares e radiculares foram separadas em feixes contendo 40 estacas e estes embrulhados em folhas de papel jornal umedecido e colocados dentro de sacos plásticos hermeticamente vedados, antes de serem armazenados em câmara fria a $4^{\circ} \mathrm{C}$. Esses materiais foram armazenados por 10, 20, ou 30 dias na câmara, além do controle sem armazenamento. Após cada período de armazenamento, as estacas foram desembrulhadas e tratadas com os reguladores vegetais.

As estacas caulinares foram tratadas com diferentes concentrações de ácido indolilbutírico (AIB) na forma de líquido dissolvido em éter: 1000, 2000, 3000 e 4000mg L-1, por 10 segundos, além do controle que foi tratado com água destilada. $\mathrm{O}$ delineamento utilizado foi o inteiramente casualizado, em esquema fatorial $4 \times 5$, com quatro períodos de armazenamento e cinco concentrações de AIB, em quatro repetições e com 10 estacas por parcela, totalizando 800 estacas. No segundo experimento, 
as estacas radiculares foram tratadas com cinco concentrações de benzilaminopurina (BAP): 300, 600, 900, 1200 e $1500 \mathrm{mg} \mathrm{L}^{-1}$, por 10 segundos, além do controle, tratado com água destilada. $\mathrm{O}$ delineamento utilizado também foi o inteiramente casualizado, em esquema fatorial $4 \times 6$, com quatro períodos de armazenamento e seis concentrações de BAP, em quatro repetições e com 10 estacas por parcela, totalizando 960 estacas.

As estacas caulinares tiveram $2 / 3$ de seu comprimento enterrado, na posição vertical, e as estacas radiculares foram totalmente enterradas na posição horizontal, e a três $\mathrm{cm}$ de profundidade, em caixas plásticas preenchidas com o substrato vermiculita de grânulos médios, e levadas para a proteção de telado com sombreamento de 50\%. As estacas foram diariamente umedecidas até a capacidade de campo do substrato e, ao final de 75 dias após o estaqueamento, foram avaliadas quanto à porcentagem de estacas enraizadas e brotadas, o número de brotos e raízes e o comprimento das brotações e raízes.

\section{RESULTADOS E DISCUSSÃO}

Não se observou interação significativa entre os fatores estudados, em ambos os experimentos, com diferença estatística entre tratamentos dentro dos fatores isolados. No primeiro experimento, detectou-se diferença estatística entre os períodos de armazenamento na porcentagem de estacas caulinares brotadas. Porém, no segundo experimento, houve diferença estatística entre os períodos de armazenamento e entre as concentrações de BAP na porcentagem de estacas radiculares enraizadas e brotadas e para o comprimento médio das raízes e das brotações, sendo nessa última variável apenas entre as concentrações de BAP.

Nas estacas caulinares, a capacidade em emitir raízes foi pequena. Conseguindo-se registrar enraizamento somente em 3\% nas estacas armazenadas por 20 dias e 3,12\% nas estacas tratadas com $1.000 \mathrm{mg} \mathrm{L}^{-1}$ de AIB (Tabela 1). Ocorreu brotação nas estacas caulinares, com estímulo a emissão de brotações em decorrência ao armazenamento em baixas temperaturas. Registrou-se 76,5\% de estacas caulinares brotadas quando essas foram armazenadas por 30 dias em baixas temperaturas, incremento de $39,5 \%$ em relação às estacas que não passaram pelo processo de armazenamento (Figura 1).

Não se detectou boa capacidade de enraizamento nas estacas caulinares, o que é diferente do encontrado na literatura para a propagação da amoreira-preta e da framboeseira negra (CAMPAGNOLO \& PIO, 2012; SILVA et al., 2012), que também pertencem ao gênero Rubus. Essa diferença pode estar relacionada às características intrínsecas de cada espécie em emitir raízes nos fragmentos destacados dos ramos. Para a amoreira-preta Xavante, YAMAMOTO et al. (2012) concluíram que a propagação por estaquia herbácea é eficiente, sem o uso de AIB.

No caso das estacas radiculares, foram registradas $54,1 \%$ de estacas enraizadas, $45 \%$ de

Tabela 1 - Porcentagem de estacas enraizadas (PEE), número médio de brotos (NMB), número médio de raízes (NMR), comprimento médio de brotos (CMB) e comprimento médio das raízes (CNR) de estacas caulinares de framboeseiras (Rubus ideaus L.) submetidas ao armazenamento a $4^{\circ} \mathrm{C}$, por diferentes períodos, e ao tratamento com ácido indolilbutírico (AIB). Lavras, UFLA, 2013.

\begin{tabular}{|c|c|c|c|c|c|}
\hline Armazenamento (dia) & PEE (\%) & NMB & NMR & $\mathrm{CMB}(\mathrm{cm})$ & $\mathrm{CMR}(\mathrm{cm})$ \\
\hline 0 & $0^{*}$ & $1,16^{*}$ & $0^{*}$ & $1,65^{*}$ & $0^{*}$ \\
\hline 10 & 2,00 & 1,31 & 0,20 & 2,09 & 0,40 \\
\hline 20 & 3,00 & 1,23 & 0,25 & 2,34 & 0,27 \\
\hline 30 & 0 & 1,18 & 0 & 2,59 & 0 \\
\hline Média & 1,25 & 1,22 & 0,11 & 2,17 & 0,17 \\
\hline 0 & $1,25^{*}$ & $1,24^{*}$ & $0,12^{*}$ & $2,44^{*}$ & $0,12^{*}$ \\
\hline 1.000 & 3,12 & 1,13 & 0,25 & 1,94 & 0,56 \\
\hline 2.000 & 0 & 1,22 & 0 & 2,00 & 0 \\
\hline 3.000 & 1,25 & 1,24 & 0,06 & 2,59 & 0,03 \\
\hline 4.000 & 0,67 & 1,27 & 0,13 & 2,10 & 0,13 \\
\hline Média & 1,26 & 1,22 & 0,11 & 2,21 & 0,17 \\
\hline $\mathrm{CV}(\%)$ & 32,35 & 17,62 & 35,65 & 35,42 & 29,79 \\
\hline
\end{tabular}

* não significativo. 


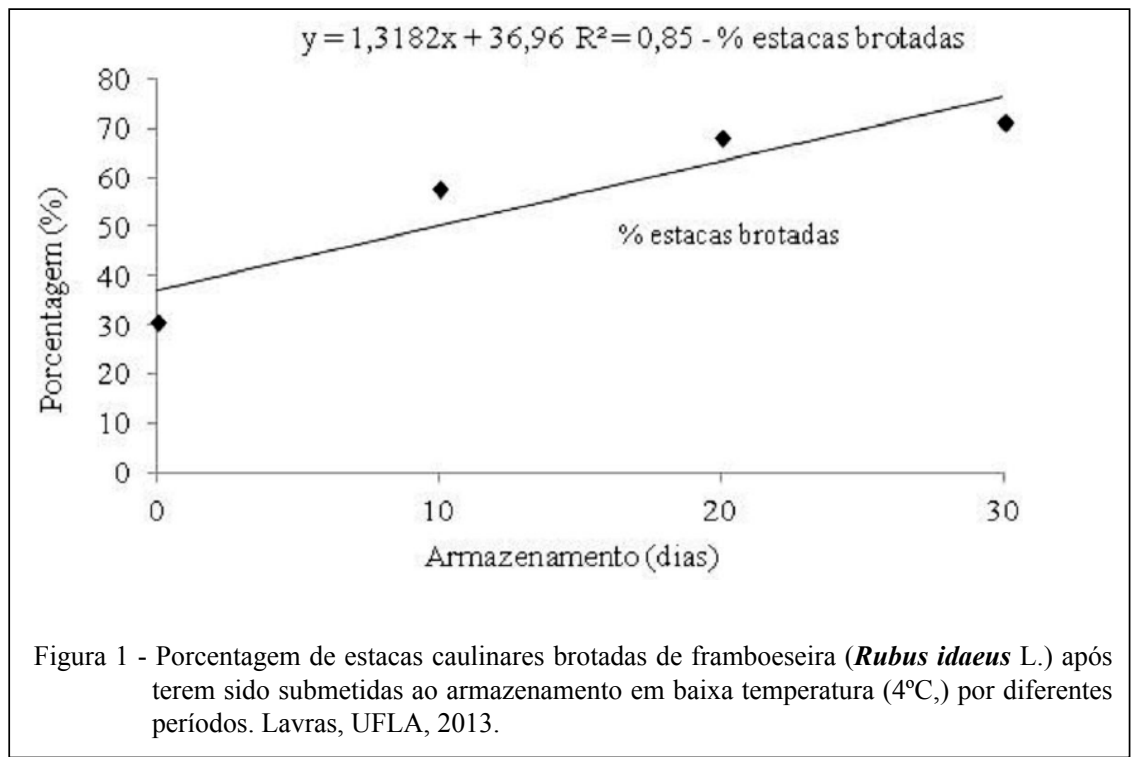

estacas brotadas e ainda raízes com comprimento médio de $6,4 \mathrm{~cm}$, em estacas que não passaram pelo armazenamento. Observou-se decréscimo linear à medida que as estacas foram armazenadas por maiores períodos a $4^{\circ} \mathrm{C}$ (Figuras 2A e 2B). Esses resultados discordam com CAMPAGNOLO \& PIO (2012), que obtiveram incrementos significativos em estacas radiculares de amoreira-preta, com o armazenamento em baixas temperaturas, possivelmente devido às condições intrínsecas da amoreira-preta em relação à framboeseira.

A aplicação de BAP nas estacas radiculares foi prejudicial, registrando-se melhores índices quando as estacas não foram tratadas com esse regulador vegetal. Foram obtidos $52,9 \%$ de estacas enraizadas e $48,1 \%$ de estacas brotadas
(Figura 3A), raízes com comprimento médio de $7,3 \mathrm{~cm}$ e brotações com $3,6 \mathrm{~cm}$ (Figura 3B), índices que foram linearmente decrescendo, à medida que as estacas foram tratadas com concentrações crescentes de BAP, possivelmente pela fitotoxidez ocasionada.

Segundo LEITZKE et al. (2010), o BAP acrescido ao meio de cultura auxilia na multiplicação in vitro de micro propágulos da framboeseira 'Batum'. Como não encontramos relatos na literatura sobre a utilização de citocininas para o estímulo de brotações em estacas radiculares, sugerimos que novos trabalhos sejam realizados, principalmente em estacas de framboeseiras, até mesmo com outras citocininas e com concentrações e tempos de tratamento diferenciados.
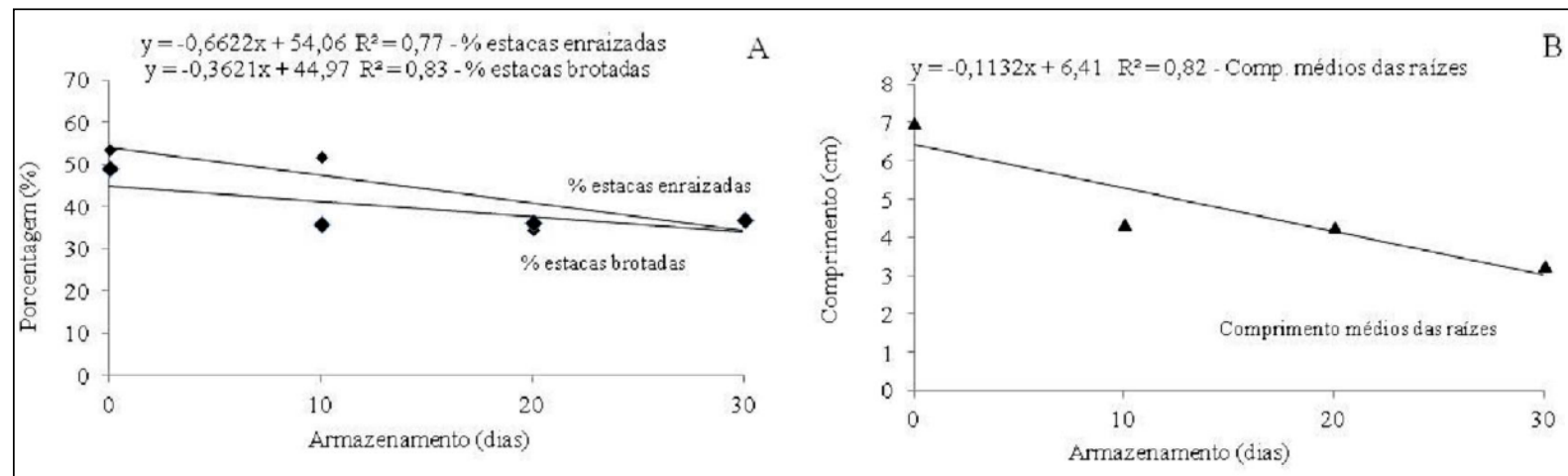

Figura 2 - Porcentagem de estacas enraizadas e brotadas (A) e comprimento médio das raízes (B) de estacas radiculares de framboeseira (Rubus idaeus L.) submetidas ao armazenamento em baixa temperatura ( $\left.4^{\circ} \mathrm{C}\right)$, por diferentes períodos. Lavras, UFLA, 2013. 

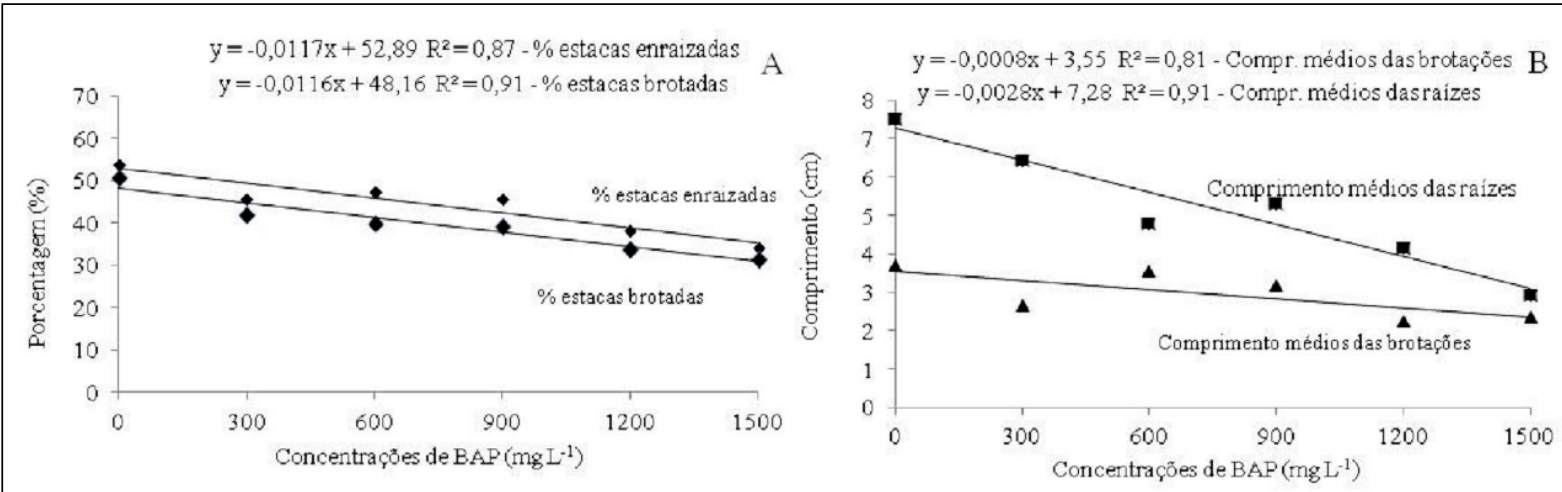

Figura 3 - Porcentagem de estacas enraizadas e brotadas (A) e comprimento médio das brotações e raízes (B) de estacas radiculares de framboeseira (Rubus idaeus L.) submetidas ao tratamento com diferentes concentrações de benzilaminopurina (BAP). Lavras, UFLA, 2013.

\section{CONCLUSÃO}

Pelos resultados obtidos e nas condições deste experimento, pode-se concluir que o uso de estacas caulinares não se mostrou viável para a produção de mudas da framboeseira e que a propagação da framboeseira por estacas radiculares se mostrou viável sem a necessidade de tratamentos com baixa temperatura ou citocinina para a indução da brotação.

\section{AGRADECIMENTOS}

Os autores agradecem à Coordenação de Aperfeiçoamento de Pessoal de Nível Superior (CAPES), Conselho Nacional de Desenvolvimento Cientifico e Tecnológico $(\mathrm{CNPq})$ e a Fundação de Amparo à Pesquisa do Estado de Minas Gerais (FAPEMIG), pelo suporte financeiro no desenvolvimento do presente trabalho.

\section{REFERÊNCIAS}

CAMPAGNOLO, M.A.; PIO, R. Enraizamento de estacas caulinares e radiculares de cultivares de amoreira-preta coletadas em diferentes épocas, armazenadas a frio e tratadas com AIB. Ciência Rural, Santa Maria, v.42, n.2, p.232-237, 2012 Disponível em: <http://www.scielo.br/scielo.php?pid=S010384782012000200008\&script=sci_arttext $>$. Acesso em: 24 out. 2013. doi: 10.1590/S0103-84782012000200008.

CELANT, V.M. et al. Armazenamento a frio de ramos portaborbulhas e métodos de enxertia de cultivares de marmeleiro. Ciência Rural, Santa Maria, v.40, n.1, p.20-24, 2010. Disponível em: <http://www.scielo.br/scielo.php?pid=S0103$84782010000100004 \&$ script $=\mathrm{sci}$ abstract\&tlng $=\mathrm{pt}>$. Acesso em: 19 out. 2013 . doi: $10.1590 / \mathrm{S} 010 \overline{3}-84782009005000223$.

CHAGAS, E.A. et al. Enraizamento de estacas lenhosas de pessegueiro e clones de umezeiros submetidos à aplicação de AIB. Ciência e Agrotecnologia, Lavras, v.32, n.3, p.986-991,
2008. Disponível em: $<$ http://www.scielo.br/scielo.php?pid=S1413$70542008000300043 \&$ script $=$ sci_arttext $>$. Acesso em: 14 jan. 2015. doi: 10.1590/S1413-70542008000300043.

CURI, P.N. et al. Qualidade de framboesas sem cobertura ou cobertas sobre o dossel e em diferentes espaçamentos. Revista Brasileira de Fruticultura, Jaboticabal, v.36, n.1, p.199-205, 2014. Disponível em: $<$ http://www.scielo.br/scielo.php?script=sci arttext\&pid=S0100-29452014000100023\&lng=pt\&nrm=iso\&tlng $=$ en $>$. Acesso em: 19 set. 2014. doi: 10.1590/0100-2945-234/13.

GUEDES, M.N.S. et al. Composição química, compostos bioativos e dissimilaridade genética entre cultivares de amoreira (Rubus spp.) cultivadas no Sul de Minas Gerais. Revista Brasileira de Fruticultura, Jaboticabal, v.36, n.1, p.206-213, 2014. Disponível em: <http://www.scielo.br/scielo. php?script $=$ sci_arttext\&pid $=$ S0100-29452014000100024\&ln $\mathrm{g}=\mathrm{pt} \& \mathrm{nrm}=\mathrm{iso} \& \operatorname{tng}=\mathrm{en}>$. Acesso em: 19 set. 2014. doi: 10.1590/0100-2945-230/13.

GUEDES, M.N.S. et al. Chemical characterization and mineral levels in the fruits of blackberry cultivars grown in a tropical climate at an elevation. Acta Scientiarum. Agronomy, Maringá, v.35, n.2, p.191-196, 2013. Disponível em: <http://www.scielo. br/scielo.php?pid=S1807-86212013000200007\&script $=$ sci arttext>. Acesso em: 18 out. 2013. doi: 10.4025/actasciagron. v35i2.16630.

HAN, H. et al. A review on the molecular mechanism of plants rooting modulated by auxin. African Journal of Biotechnology, South Africa, v.8, n.3, p.348-353, 2009. Disponível em: $<$ http:// www.ajol.info/index.php/ajb/article/view/59811>. Acesso em: 19 out. 2013.

LEITZKE, L.N. et al. Influência do meio de cultura, tipo e concentração de citocininas na multiplicação in vitro de amoreirapreta e framboeseira. Ciência e Agrotecnologia, Lavras, v.34, n.2, p.352-360, 2010. Disponível em: <http://www.scielo.br/scielo. php?pid=S1413-70542010000200012\&script $=$ sci_arttext $>$. Acesso em: 22 out. 2013. doi: 10.1590/S1413-70542010000200012.

MARO, L.A.C. et al. Bioactive compounds, antioxidant activity and mineral composition of fruits of raspberry cultivars grown in subtropical areas in Brazil. Fruits, Paris, v.68, p.209-217, 2013. 
Disponível em: <http://www.fruits-journal.org/articles/fruits/ abs/2013/03/fruits130068/fruits130068.html . Acesso em: 14 jan. 2015. doi: 10.1051/fruits/2013068.

MARO, L.A.C. et al. Ciclo de produção de cultivares de framboeseiras (Rubus idaeus) submetidas à poda drástica nas condições do sul de Minas Gerais. Revista Brasileira de Fruticultura, Jaboticabal, v.34, n.2, p.435-441, 2012. Disponível em: <http://www.scielo.br/ scielo.php?pid=S0100-29452012000200016\&script=sci_arttext $>$. Acesso em: 17 out. 2013. doi: 10.1590/S0100-29452012000200016.

MARO, L.A.C. et al. Environmental and genetic variation in the post-harvest quality of raspberries in subtropical areas in Brazil. Acta Scientiarum. Agronomy, Maringá, v.36, n.3, p.323-328, 2014. Disponível em: <http://periodicos.uem.br/ojs/index.php/ ActaSciAgron/article/view/18050>. Acesso em: 19 set. 2014. doi: 10.4025/actasciagron.v36i3.18050.

MOURA, P.H.A. et al. Fenologia e produção de cultivares de framboeseiras em regiões subtropicais no Brasil. Pesquisa Agropecuária Brasileira, Brasília, v.47, n.12, p.1714-1721, 2012. Disponível em: <http://www.scielo.br/scielo.php?pid=S0100204X2012001200006\&script=sci_arttext $>$. Acesso em: 21 out. 2013. doi: 10.1590/S0100-204X2012001200006.

PAGOT, E. Cultivo de pequenas frutas: amora-preta, framboesa e mirtilo. Porto Alegre: EMATER/RS-ASCAR, 2006. 41p.

PATTO, L.S. et al. Vegetative propagation of redberry using refrigeration, IBA and BAP. Revista Ciências Agrárias, v.56, n.Supl., p.140-144, 2013. Disponível em: <http://www.periodicos.ufra.edu.br/index.php?j ournal $=$ ajaes\&page $=$ article\&op $=$ view\&path $\% 5 \mathrm{~B} \% 5 \mathrm{D}=1441>$. Acesso em: 19 set. 2014. doi: 10.4322/rca.2013.094.
RASEIRA, M.C.B. et al. Aspectos técnicos da cultura da framboeseira. Pelotas: Embrapa Clima Temperado, 2004. 22p. (Documentos, 120).

SILVA, K.N. et al. Produção de mudas de framboeseira negra por diferentes métodos de propagação vegetativa. Ciência Rural, Santa Maria, v.42, n.3, p.418-422, 2012. Disponível em: <http://www.scielo.br/scielo.php?pid=S010384782012000300006\&script=sci_arttext $>$. Acesso em: 23 out. 2013. doi: $10.1590 / \mathrm{S} 0103-84782012000300006$.

SOUZA, V.R. et al. Determination of the bioactive compounds, antioxidant activity and chemical composition of Brazilian blackberry, red raspberry, strawberry, blueberry and sweet cherry fruits. Food Chemistry, v.156, p.362-368, 2014a. Disponível em: <http://ac.els-cdn.com/S0308814614001770/1s2.0-S0308814614001770-main.pdf?_tid=f1425554-bbf4-11e3aa89-00000aab0f6b\&acdnat $=1396614824 \quad 0$ da62 cdedaf5c9f8 5864d781725edb24>. Acesso em: 02 abr. 2014. doi: 10.1016/j. foodchem.2014.01.125.

SOUZA, V.R. et al. Evaluation of the Jelly Processing Potential of Raspberries Adapted in Brazil. Journal of Food Science, v.79, p.407-412, 2014b. Disponível em: <http://onlinelibrary.wiley.com/ doi/10.1111/1750-3841.12354/abstract >. Acesso em: 14 jan. 2015. doi: $10.1111 / 1750-3841.12354$.

YAMAMOTO, L.Y. et al. Substratos no enraizamento de estacas herbáceas de amora-preta Xavante. Ciência Rural, Santa Maria, v.43, n.1, p.15-20, 2013. Disponível em: <http://www.scielo. br/scielo.php?pid=S0103-84782013000100003\&script $=$ sci arttext>. Acesso em: 07 nov. 2013. doi: 10.1590/S010384782012005000135 . 